\title{
Ouvidoria universitária, uma cultura em expansão
}

University listening, an expanding culture

\section{La defensoría universitaria, una cultura en expansión}

Carmen Lúcia de Araújo Calado

Em setembro de 2005 fiz um levantamento das ouvidorias universitárias no País, buscando conhecer não apenas o número de instituições de ensino que as adotavam, mas, sobretudo compreender a função dessas ouvidorias nas universidades. Expondo os resultados daquela pesquisa no Fórum Nacional de Ouvidores Universitários, os dados surpreenderam as pessoas. Em 2009, fiz novo levantamento, que apresentei no IX Fórum Nacional, tendo a surpresa sido ainda maior, pois o crescimento havia muito acima do esperado, cerca de $439 \%$.

Esse aumento se deu, entre vários motivos, porque uma lei obriga as instituições de ensino superior a criarem e manterem ouvidorias. Porém, obrigadas ou não, as ouvidorias são uma realidade irreversível nas instituições de ensino superior. Não interessa tanto saber se as ouvidorias estão majoritariamente em instituições públicas ou privadas, porque a nossa clientela é a mesma.

A maior parte da demanda de todas elas não surge, como se poderia imaginar, dos alunos, mas das comunidades na qual as instituições estão instaladas. As pessoas repercutem notícias da mídia e, quando o assunto envolve uma ou outra instituição, buscam as ouvidorias para obter esclarecimentos. As questões internas mais demandadas dizem respeito ao relacionamento aluno-professor e aos critérios de avaliação das provas regulares.

1 Ouvidora-geral da Universidade Federal do Rio Grande do Norte (UFRN) e presidente do Fórum Nacional de Ouvidores Universitários (FNOU). 
Internamente, a quantidade de demanda é um termômetro, o indicador mais importante para sabermos onde devemos atuar, onde devemos pesquisar para buscar a origem dos problemas. Mas também damos muitas informações e esclarecemos muitas dúvidas que chegam de todos os tipos de público com os quais lidamos: alunos, professores, pais, populações da região na qual estamos estabelecidos etc.

Na Universidade Federal do Rio Grande do Norte (UFRN), a ouvidoria foi responsável por várias mudanças, agindo diretamente para corrigir distorções. Foi assim com a mudança dos critérios de avaliação dos alunos e nas negociações que resultaram na manutenção de professores substitutos, a pedido também dos alunos.

Os administradores deveriam valorizar mais as ouvidorias, porque são elas, com certeza, o melhor lugar para conhecerem onde estão os problemas e onde eles devem atuar para proporcionar satisfação aos nossos públicos.

Essa é uma cultura que ainda está nascendo, mas que tem tudo para florescer em pouco tempo, proporcionando integração, participação e, desse modo, estimulando o sentimento de pertencimento e de cidadania. 